\title{
Application of Supercapacitors in Photovoltaic Power Generation System
}

\author{
Shing-Lih Wu, ${ }^{1}$ Shin-Shiuan Li, ${ }^{2}$ Feng-Chang Gu, ${ }^{2}$ \\ Po-Hung Chen, ${ }^{3}$ and Hung-Cheng Chen ${ }^{2 *}$ \\ ${ }^{1}$ Department of Electrical Engineering, National Taitung Junior College \\ No. 889, Jhengci N. Rd., Taitung 95045, Taiwan (R.O.C.) \\ ${ }^{2}$ Department of Electrical Engineering, National Chin-Yi University of Technology \\ No. 57, Sec. 2, Zhongshan Rd., Taiping Dist., Taichung 41170, Taiwan (R.O.C.) \\ ${ }^{3}$ Department of Electrical Engineering, St. John's University \\ No. 499, Sec. 4, Tam King Road, Tamsui District, New Taipei City 25135, Taiwan, (R.O.C.)
}

(Received April 20, 2019; accepted September 5, 2019)

Keywords: photovoltaic power generation, supercapacitor, maximum power point tracking converter, power quality

In view of the intermittent and unstable output voltage of the photovoltaic power generation module, a supercapacitor is designed as the control system to improve the power quality and power supply continuity of the photovoltaic power generation system. The whole circuit includes a maximum power point tracking converter, a boost converter, a Hall element, a waveform recorder, and a supercapacitor bank. Because the output current of each solar photovoltaic module is very important for the control of the solar power generation system with a supercapacitor bank, a sensing circuit for accurately detecting the output current and current change rate of the solar power generation system is presented. When the sunshine is sufficient, the control system dispatches the output current of the solar photovoltaic module and provides power to the supercapacitor bank and the load terminal; when the sky is cloudy, the control system discharges the energy stored in the supercapacitor as an uninterruptible power source and provides power to the load such that the load terminal voltage is stable. The measured results show that the control system can effectively suppress the output voltage fluctuation of the photovoltaic power generation module, improve the power quality, and enhance the reliability of load power consumption.

\section{Introduction}

With the progress of civilization, traditional petroleum energy is consumed daily, and the demand for energy is increasing gradually. However, international petroleum energy has been in short supply, the price is rising daily, and the excessive use of petroleum energy and exploitation will cause the earth's greenhouse effect. Because of the above reasons, the

*Corresponding author: e-mail: hcchen@ncut.edu.tw

https://doi.org/10.18494/SAM.2019.2502 
development and demand for renewable energy will increase daily. ${ }^{(1-5)}$ Among the different types of renewable energy, photovoltaic energy is undoubtedly the ideal green energy for sustainable development. Because of the advantages of endless sunlight, inexhaustible use, pollution-free and simple setup, no labor exploitation, easy expansion of power generation capacity, high reliability, and emergency power supply suitable for remote areas as backup capacity, photovoltaic energy is suitable for ecological conservation, environmental protection, and carbon dioxide emission suppression. Thus, the world is actively developing photovoltaic energy. ${ }^{(6,7)}$ Photovoltaic power generation is a new type of renewable energy, which creates a new life form for human beings and makes human beings enter an era of energy saving and environmental pollution reduction. The supercapacitor is a type of physical secondary power supply with superstrong energy storage capacity and strong pulse power. It is a new type of energy storage device between the storage battery and the traditional capacitor. The supercapacitor is developed according to the electrochemical equilibrium theory. The state of the electrode is idealized. Its surface charge will attract anisotropic ions in the surrounding electrolyte solution and make these ions adhere to it. The electrode and the electrolyte surface form double charges to form double-layer capacitance. Because the distance between the two charge layers is very small and the special electrode structure is adopted, the surface of the electrode is increased, resulting in a great capacity. The supercapacitor can achieve energy storage by polarization. ${ }^{(8-11)}$ It is an electrochemical element, but its energy storage process does not require a chemical reaction and is reversible. Moreover, as a new energy storage element, ${ }^{(12-15)}$ the supercapacitor has clear advantages over a storage battery and an ordinary electrolytic capacitor, such as high power density, long cycle life, fast charging and discharging, low leakage current, small resistance, safety, and environmental protection. ${ }^{(16-20)}$

In this study, the application of a supercapacitor to a photovoltaic power generation system is presented. Its circuit includes a maximum power point tracking converter, a boost converter, a Hall element, a waveform recorder, and a supercapacitor bank. To solve the problem of the unstable output voltage of the photovoltaic power generation module, a supercapacitor is designed as an energy storage device to improve the power quality and power supply continuity of the photovoltaic power generation system. Finally, the charging and discharging parts of the supercapacitor bank are measured on the basis of photovoltaic energy. A single supercapacitor is $2.7 \mathrm{~V}$ and $50 \mathrm{~F}$, and 60 supercapacitors are connected in series and parallel to $27 \mathrm{~V}$ and $30 \mathrm{~F}$ modules. The load resistance is $50 \Omega$. The measured results show that when the initial voltages of the supercapacitor bank are 19.6, 19.7, and $19.2 \mathrm{~V}$, and when the photovoltaic power system is fully charged under normal operating conditions, the charging times are 76,90 , and $187 \mathrm{~s}$, respectively. If the photovoltaic system is interrupted in a short time, the supercapacitor bank can still provide energy to the load, which can maintain the load for 49, 47, and $23 \mathrm{~s}$, respectively.

\section{Measurement Circuits and Testing Procedures}

The application research of supercapacitors in the photovoltaic power generation system proposed in this study includes the photovoltaic power generation module, power generation 
control system, and load. The schematic diagram of the proposed control system is shown in Fig. 1. The power generation control system includes a maximum power point tracking converter, a boost converter, a Hall element, a waveform recorder, and a supercapacitor bank. The output current of the solar power generation system varies with the intensity of solar sunshine. Because the main purpose of this study is to use the output current of the system to control the charging and discharging of the power generation system, it is important to accurately detect the output current and current change rate of the solar power generation system. A sensing circuit for measuring the magnitude and change rate of each important output current and voltage in a large number of systems is presented. The sensing data are analyzed to control the charging and discharging actions of the solar power system in this study. This is the active principle of the photovoltaic power generation control system: the photovoltaic power generation module generates energy to the energy storage device and load through the maximum power point tracking converter, the boost converter can make the load have a stable output voltage, and the supercapacitor bank is the energy storage device in this system.

(1) Photovoltaic Power Generation Module

The photovoltaic power generation module used in this study is produced by the New Solar Energy Technology Company in China. The model is the D6M300H3A single-crystal solar photovoltaic module. As shown in Fig. 2, the actual size of the photovoltaic power generation module is $1640 \times 992 \mathrm{~mm}^{2}$, and it is composed of 60 single-crystal silicon cells. One of them is listed as 6 , totaling 10 rows. The maximum power output of the photovoltaic power generation module is $300 \mathrm{~W}$. Table 1 shows the specifications of the photovoltaic power generation module provided by the manufacturer.

(2) Maximum Power Point Tracking Converter

The maximum power point tracking converter used in the system has voltage ranges of $7-40 \mathrm{~V}$ at the input end and $7-29 \mathrm{~V}$ at the output end. To match the voltage of the

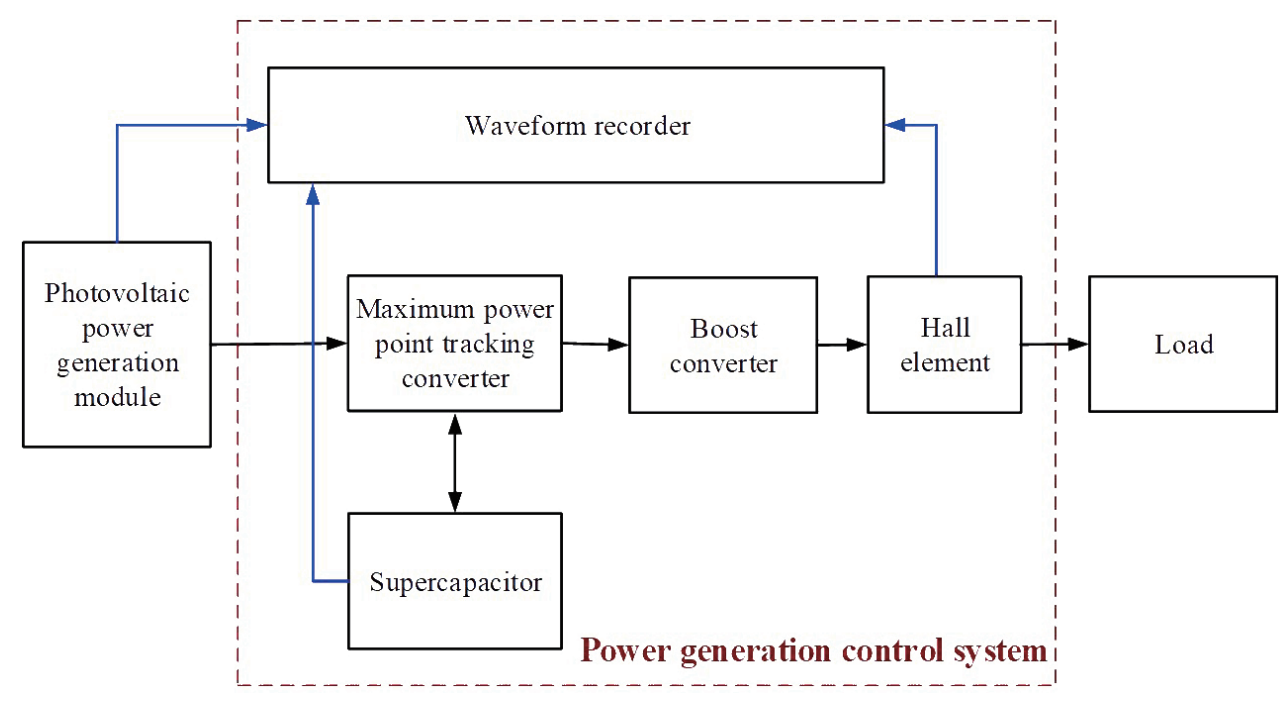

Fig. 1. (Color online) Schematic diagram of the proposed control system. 


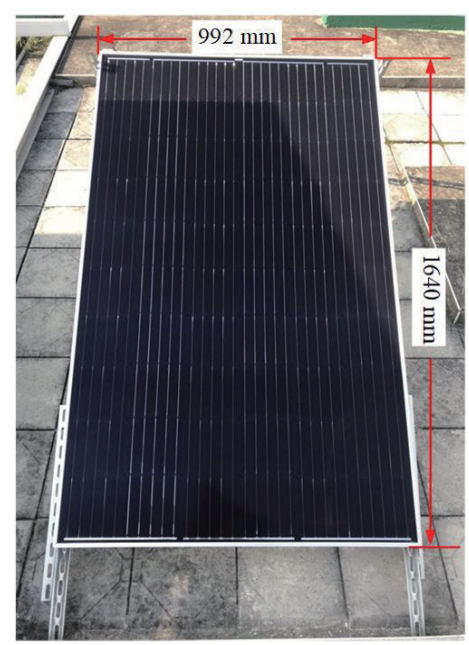

Table 1

Specifications of the photovoltaic power generation module.

Rated maximum output power $\left(P_{\max }\right) \quad 300 \mathrm{~W}$

Open-circuit voltage $\left(V_{o c}\right) \quad 39.39 \mathrm{~V}$

Short-circuit current $\left(I_{s c}\right)$

Maximum output power point voltage $\left(V_{p m}\right) \quad 32.09 \mathrm{~V}$

Maximum output power point current $\left(I_{p m}\right) \quad 9.35 \mathrm{~A}$

Fig. 2. (Color online) Photovoltaic power generation module.

supercapacitor bank, the output voltage of the maximum power point tracking converter is set to $24 \mathrm{~V}$ and the maximum charging current is $26 \mathrm{~A}$. The system can charge the supercapacitor and provide energy to the load with the maximum power output and voltage reduction to the set output voltage.

(3) Boost Converter

The input voltage range of the boost converter used in the system is $12-48 \mathrm{~V}$, and the output voltage is set to $48 \mathrm{~V}$. The working principle of the boost converter is that it can convert the variable input voltage into a fixed output voltage. In this study, the boost converter is used to increase the voltage requirement from the voltage to the load and to convert the variable input voltage into a fixed output voltage when the supercapacitor bank discharges. The output voltage supplies the load side to increase the action time of the load. Its internal circuit is composed of a boost main circuit, a drive circuit, an auxiliary power supply, a signal conditioning circuit, and a main control circuit, as shown in Fig. 3.

(4) Supercapacitor Bank

In this study, the supercapacitors produced by NESSCAP Company are used as energy storage components. The model is ESHSR-0050C0-002R7, and the single size is $2.7 \mathrm{~V}$ and $50 \mathrm{~F}$. In this study, 10 series, 6 parallel, or a total of 60 supercapacitors are used. They are connected in series and parallel to $27 \mathrm{~V}$ and $30 \mathrm{~F}$ supercapacitors. The size of these supercapacitors is $240 \times 208 \mathrm{~mm}^{2}$, as shown in Fig. 4. The specifications and performance characteristics of the different supercapacitors are also different. Table 2 shows the specifications of a single supercapacitor provided by NESSCAP Company.

(5) Hall Element and Waveform Recorder

To ensure the accuracy of solar panel measurement, a Hall element is used to measure the current value of a solar panel and convert it into relative voltage. A waveform recorder is then used to record the measured value. 


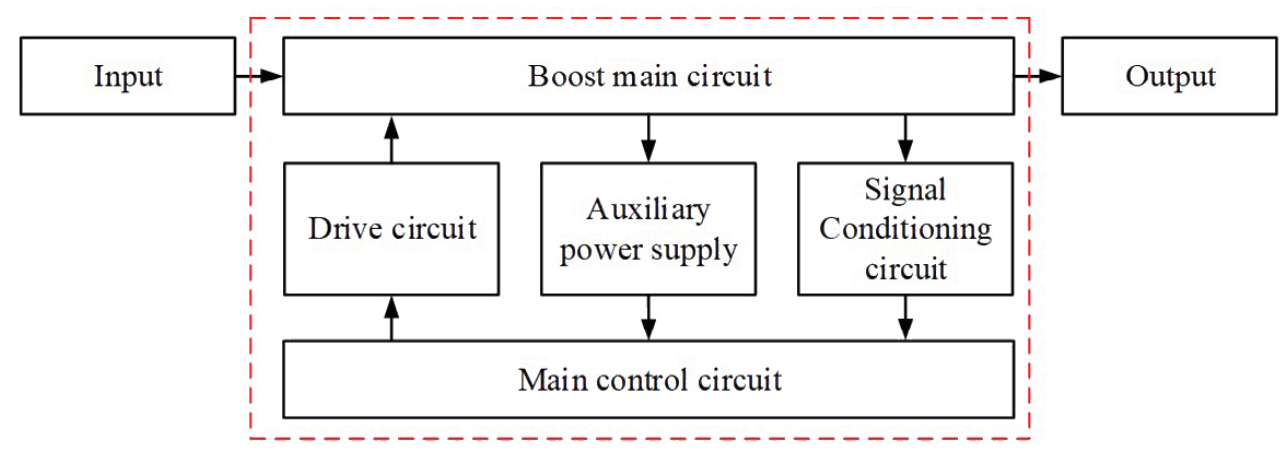

Fig. 3. (Color online) Schematic diagram of the boost converter.

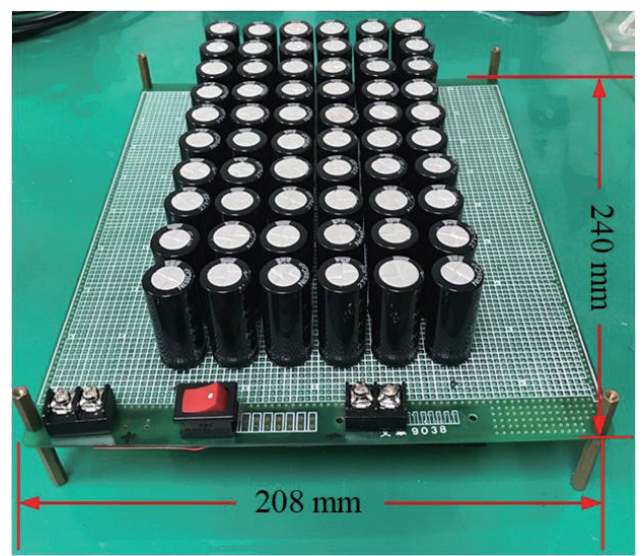

Table 2

Specifications of a single supercapacitor.

Rated voltage $2.7 \mathrm{~V}$

Rated capacitance $\quad 50 \mathrm{~F}$

Rated current $\quad 10.8 \mathrm{~A}$

Surge voltage $\quad 2.85 \mathrm{~V}$

Maximum current $>30 \mathrm{~A}$

Equivalent series resistance (ESR) $\mathrm{m} \Omega$

Fig. 4. (Color online) Energy storage devicesupercapacitor bank.

As mentioned above, the actual circuit appearance of the power generation control system is shown in Fig. 5. Firstly, in this study, we make the photovoltaic power generation module generate electricity and make the circuit operate normally under the irradiation of a solar light source. The solar illumination is about $900 \mathrm{~W} / \mathrm{m}^{2}$ when the maximum power point tracking converter charges the supercapacitor bank and the load output is stable. In the process, the input end of the maximum power point tracking converter is connected to the output end of the photovoltaic power generation module, and the boost converter is connected to the output end first. A resistor $(50 \Omega)$ is connected to the output end of the boost converter as the load end, and then the $27 \mathrm{~V}$ and $30 \mathrm{~F}$ supercapacitor banks are connected to the output end of the maximum power point tracking converter. At this time, the system not only maintains the action of the load but also begins to charge the supercapacitor bank. Finally, we show the situation wherein the power output of the photovoltaic power generation module is insufficient, and the supercapacitor bank is discharged to the load by the maximum power point tracking converter. When the power supply is interrupted, the photovoltaic power generation module is disconnected first. In this case, the supercapacitor bank provides energy to the load through the maximum power point tracking converter. The control system action flowchart is shown in Fig. 6. 


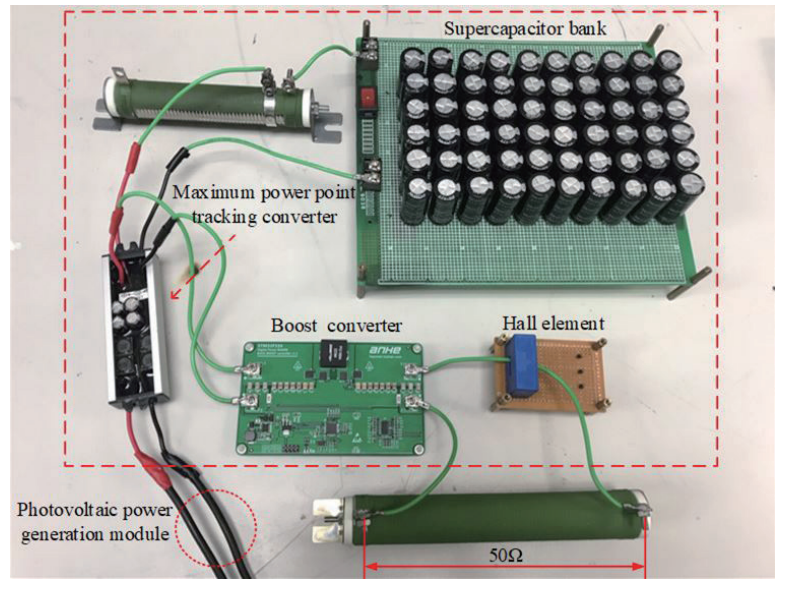

Fig. 5. (Color online) Appearance of actual circuit.

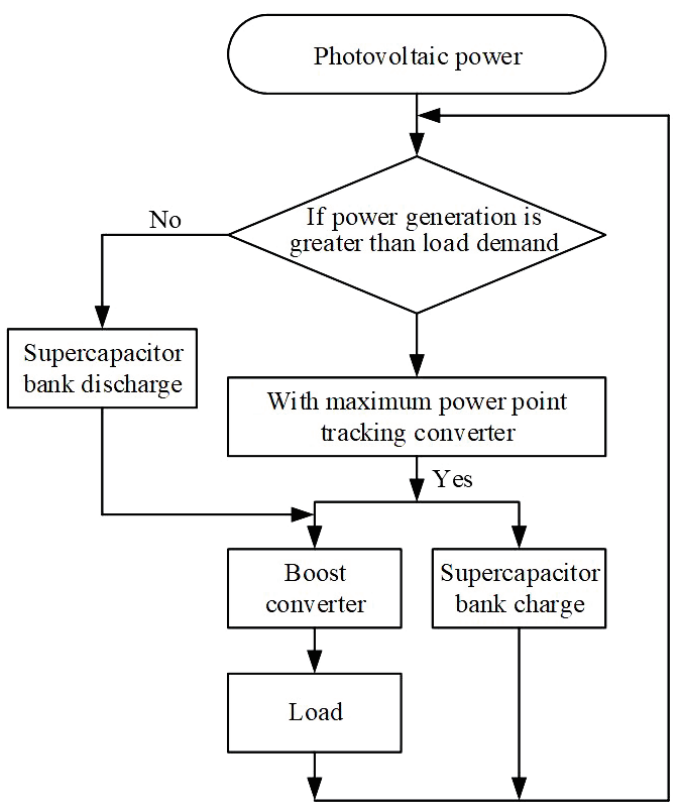

Fig. 6. Action flowchart of control system.

The measurement process is mainly divided into two parts. The first part is to charge the supercapacitor bank using the maximum power point tracking converter and output the load steadily. When the photovoltaic power generation module is supplied to the supercapacitor bank and the load, the generating energy will charge the supercapacitor bank through the maximum power point tracking converter while simultaneously supplying the load. At this time, to make the series current-limiting resistor of the supercapacitor bank in the system have a larger charging current, the required current-limiting resistor is determined, and the series current-limiting resistor can limit the charging current to no more than the charging current specification of the maximum power point tracking converter. The second part is that the supercapacitor bank discharges to the load through the maximum power point tracking converter. If the photovoltaic power generation module is covered by clouds, it cannot provide energy to the load. At this time, the energy needed by the load is supplied to the load through the maximum power point converter to the boost converter by the discharge action of the supercapacitor bank. Note that the experiment is performed outdoors; thus, the charging/ discharging actions of the system will change under different weather conditions.

\section{Measurement Results}

According to the application of the supercapacitor in the photovoltaic power generation system proposed in this study, firstly, the supercapacitor bank is charged by the maximum power point tracking converter, which has the function of stable output at the load, and the supercapacitor bank discharges at the load through the maximum power point tracking converter to maintain the stable output power at the load. The supercapacitor bank is charged/discharged 
in two parts. The current-limiting resistor used in the charging part of the supercapacitor bank is calculated according to the specifications of the maximum power point tracking converter used. The series current-limiting resistor is $0.92 \Omega$, which has better charging/discharging times and a larger charging current. However, because there is no single current-limiting resistor, the current-limiting resistor of $1 \Omega$ is used as the better testing condition. Two types of current-limiting resistors, 1.5 and $1.9 \Omega$, are added to the test for comparison in this study. It is divided into series current-limiting resistors of $1,1.5$, and $1.9 \Omega$. The measured results of charge/discharge for the above three cases are shown in Figs. 7, 8, and 9, respectively.

The first part is the charging measurement of the supercapacitor bank using the maximum power point tracking converter. The charging waveform of the supercapacitor bank is recorded and analyzed by the measurement process. When measuring, the solar illumination outside is about $900 \mathrm{~W} / \mathrm{m}^{2}$, and the input of the maximum power point tracking converter is connected to the output end of the photovoltaic power generation module. The output end of the maximum power point tracking converter is connected to a $27 \mathrm{~V}$ and $30 \mathrm{~F}$ supercapacitor bank on one side, and the current-limiting resistor is connected in series with the supercapacitor bank. On the

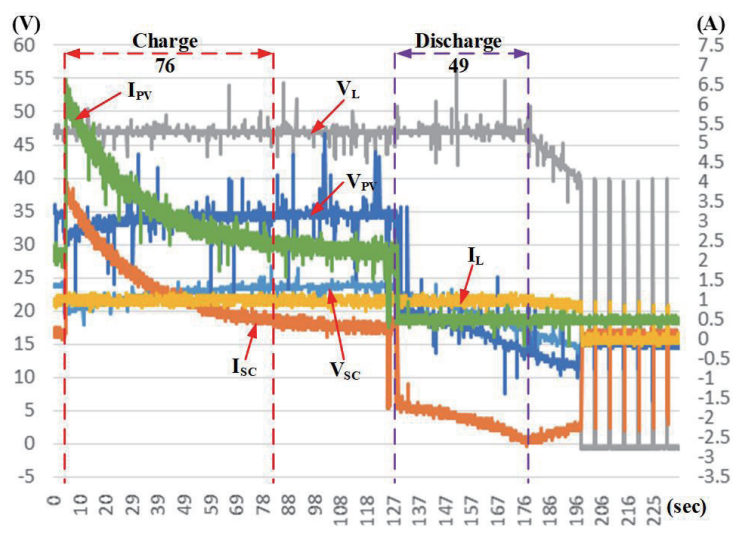

Fig. 7. (Color online) Measured waveforms of series current-limiting resistor of $1 \Omega$ during charge/ discharge.

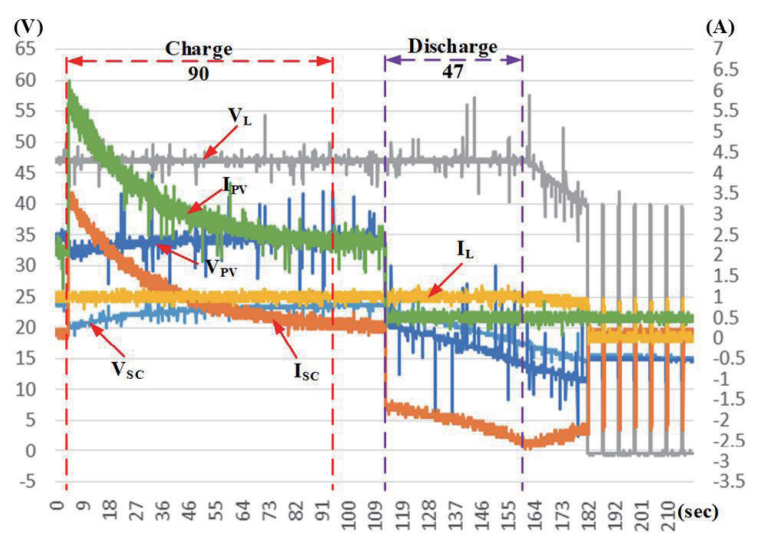

Fig. 8. (Color online) Measured waveforms of series current-limiting resistor of $1.5 \Omega$ during charge/ discharge.

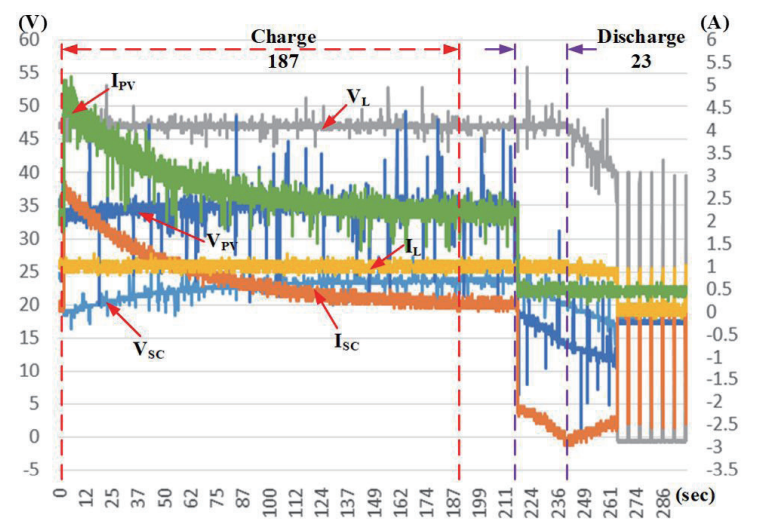

Fig. 9. (Color online) Measured waveforms of series current-limiting resistor of $1.9 \Omega$ during charge/discharge. 
other side, the input end of the boost converter is connected to the output end of the maximum power point tracking converter, and the $50 \Omega$ resistor is connected to the output of the boost converter. As the load end, the charging waveform is recorded, and the voltage and current signals and charging time are analyzed.

In this study, the charging action of the series current-limiting resistor of $1 \Omega$ is described in detail. As shown in Fig. 10, the charging waveform can be divided into three intervals to explain the changes in voltage and current, which are described as follows:

(1) Time: $t<t_{0}$

The operation of this interval system only maintains the stable output of the voltage at the load, which means that the output end of the maximum power point tracking converter is connected only to one end of the load. At this time, the voltage and current at the load are $47.5 \mathrm{~V}$ and $960 \mathrm{~mA}$, respectively. When only the load is connected, the input voltage of the maximum power point tracking converter is $35 \mathrm{~V}$, which represents the photovoltaic power generation module voltage of $35 \mathrm{~V}$, and the maximum power point tracking converter input current is $2.16 \mathrm{~A}$, which represents the photovoltaic power generation module current of $2.16 \mathrm{~A}$. In the measurement case, since the other output terminal of the maximum power point tracking converter is not connected to the supercapacitor bank, it can be seen that the set output voltage of the maximum power point tracking converter is $24 \mathrm{~V}$.

(2) Time: $t_{0} \leq t<t_{1}$

When $t=t_{0}$, the supercapacitor bank is connected to the other output terminal of the maximum power point tracking converter at the same time. The initial charging voltage of the supercapacitor bank is $19.6 \mathrm{~V}$. The voltage of the photovoltaic power generation module will be changed to $31.6 \mathrm{~V}$, the current is $6.56 \mathrm{~A}$, and the supercapacitor bank current is $3.68 \mathrm{~A}$ when the initial charging voltage of the supercapacitor bank is $19.6 \mathrm{~V}$. At this time, the current of the supercapacitor bank is the maximum current of the charging action. The voltage and current of the load are still maintained at $47.5 \mathrm{~V}$ and $960 \mathrm{~mA}$, respectively. Then, when $t_{0}<t<t_{1}$, the charging waveform of the supercapacitor bank is exponential, and when the supercapacitor bank is gradually charged to full voltage $(24 \mathrm{~V})$, the charging current will gradually decrease. At this time, the load voltage and current will remain at $47.5 \mathrm{~V}$ and $960 \mathrm{~mA}$, respectively.

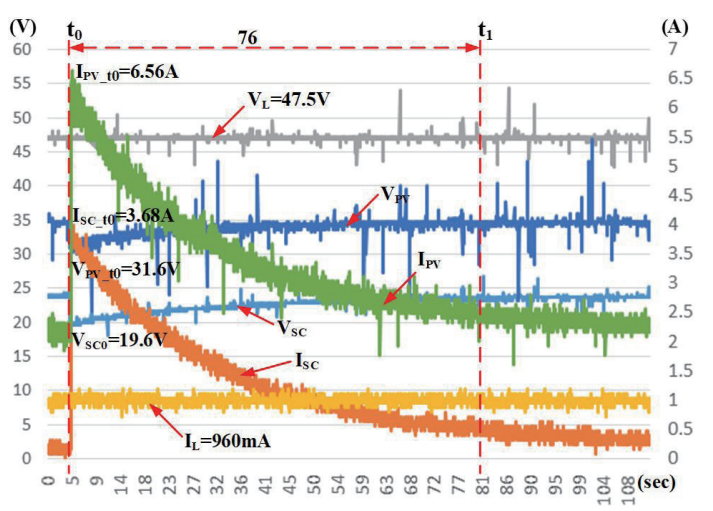

Fig. 10. (Color online) Measured waveforms of series current-limiting resistor of $1 \Omega$ during charging. 
It can be seen from the above description that when time $t_{0}<t<t_{1}$, the system action measurement results show that the supercapacitor bank can charge and the load can also maintain the required voltage, indicating that the photovoltaic power generation module of the system during the experiment can generate enough energy for both the supercapacitor bank and the load.

(3) Time: $t \geq t_{1}$

When $t \geq t_{1}$, the supercapacitor bank has entered the state of full charge, and the voltage of the supercapacitor bank has been increased to $24 \mathrm{~V}$. At this time, the current of the supercapacitor bank has gradually decreased to $0 \mathrm{~A}$. The voltage of the photovoltaic power generation module is $34.8 \mathrm{~V}$ and the current is $2.32 \mathrm{~A}$. The voltage and current of the load are still maintained at $47.5 \mathrm{~V}$ and $960 \mathrm{~mA}$, respectively.

The charging actions of the series current-limiting resistors of $1.5 \Omega$ and $1.9 \Omega$ are the same as that of the series current-limiting resistor of $1 \Omega$. Therefore, the measured values are presented in tabular form. Table 3 shows the charge numerical analysis of the series currentlimiting resistor of $1.5 \Omega$, Fig. 11 shows the measured waveform of the series current-limiting resistor of $1.5 \Omega$, Table 4 shows the charge numerical analysis of the series current-limiting resistor of $1.9 \Omega$, and Fig. 12 shows the measured waveform of the series current-limiting resistor of $1.9 \Omega$.

According to the above measured waveforms and analyses, when the photovoltaic power generation module generates enough power to supply the supercapacitor bank and the load, it can be obtained that when the system action charges the supercapacitor bank and maintains

Table 3

Charge numerical analysis of series current-limiting resistor of $1.5 \Omega$.

\begin{tabular}{lcccc}
\hline Series current-limiting resistor of $1.5 \Omega$ & $t<t_{0}$ & $t=t_{0}$ & $t_{0}<t<t_{1}$ & $t \geq t_{1}$ \\
\hline$V_{P V}(\mathrm{~V})$ & 34.8 & 32.8 & The supercapacitor & 34.8 \\
$I_{P V}(\mathrm{~A})$ & 2.08 & 6.16 & bank charges & 2.24 \\
$V_{S C}(\mathrm{~V})$ & - & 19.7 & exponentially. & 24 \\
$I_{S C}(\mathrm{~A})$ & - & 3.44 & & 0.4 \\
$V_{L}(\mathrm{~V})$ & 47.5 & 47.5 & 47.5 & 47.5 \\
$I_{L}(\mathrm{~mA})$ & 960 & 960 & 960 & 960 \\
\hline
\end{tabular}

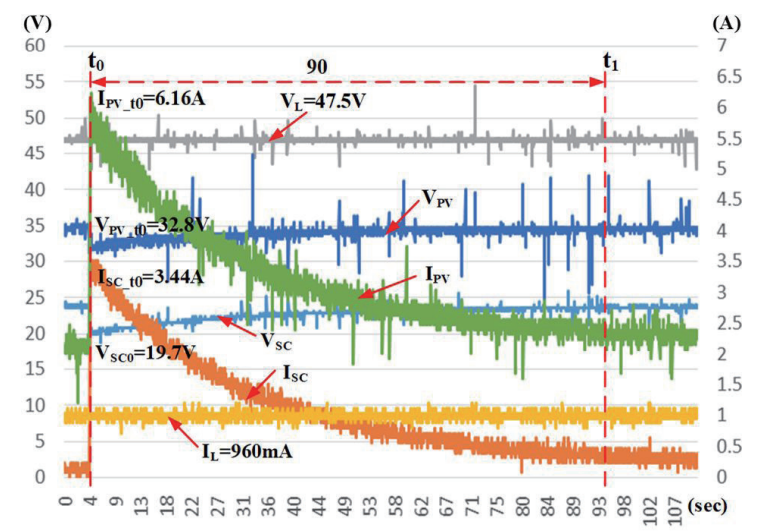

Fig. 11. (Color online) Measured waveforms of series current-limiting resistor of $1.5 \Omega$ during charging. 
Table 4

Charge numerical analysis of series current-limiting resistor of $1.9 \Omega$.

\begin{tabular}{lcccc}
\hline Series current-limiting resistor of $1.9 \Omega$ & $t<t_{0}$ & $t=t_{0}$ & $t_{0}<t<t_{1}$ & $t \geq t_{1}$ \\
\hline$V_{P V}(\mathrm{~V})$ & 35.6 & 32.8 & The supercapacitor & 34.8 \\
$I_{P V}(\mathrm{~A})$ & 2.16 & 5.12 & bank charges & 2.24 \\
$V_{S C}(\mathrm{~V})$ & - & 19.2 & exponentially. & 24 \\
$I_{S C}(\mathrm{~A})$ & - & 2.64 & & 0.4 \\
$V_{L}(\mathrm{~V})$ & 47.5 & 47.5 & 47.5 & 47.5 \\
$I_{L}(\mathrm{~mA})$ & 960 & 960 & 960 & 960 \\
\hline
\end{tabular}

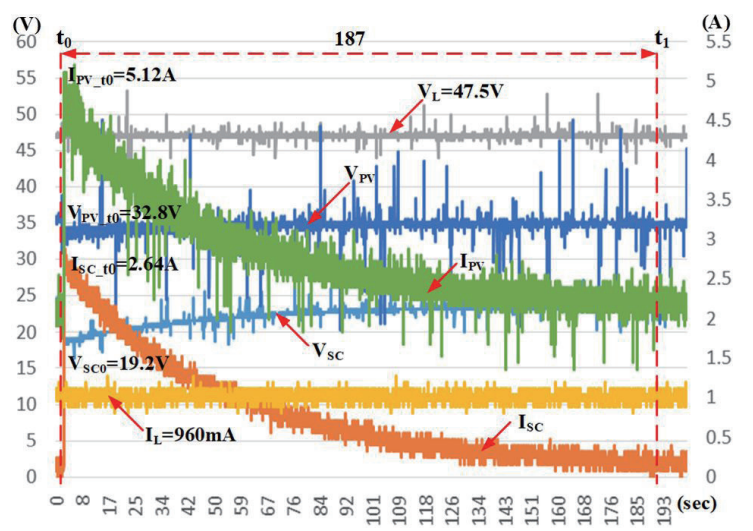

Fig. 12. (Color online) Measured waveforms of series current-limiting resistor of $1.9 \Omega$ during charging.

the energy of the load for the series current-limiting resistor of $1 \Omega$, the initial voltage of the supercapacitor bank is $19.6 \mathrm{~V}$, and the charging time to the full voltage $(24 \mathrm{~V})$ is about 76 s. The series current-limiting resistor is $1.5 \Omega$, the initial voltage of the supercapacitor bank is $19.7 \mathrm{~V}$, and the charging time is about $90 \mathrm{~s}$ when charging to the full voltage of $24 \mathrm{~V}$. The initial voltage of the supercapacitor bank is $19.2 \mathrm{~V}$ when the series current-limiting resistor is $1.9 \Omega$, and the charging time is about $187 \mathrm{~s}$ when charging to the full voltage of $24 \mathrm{~V}$. It can still maintain the operation of the load, and its voltage and current are maintained at $47.5 \mathrm{~V}$ and $960 \mathrm{~mA}$, respectively.

The second part is the measurement of the supercapacitor bank discharging to the load through the maximum power point tracking converter. The discharging waveform of the supercapacitor bank is recorded and analyzed by the measurement process. To simulate the power supply interruption of the photovoltaic power generation module and make the supercapacitor bank act as a continuous power supply, the photovoltaic power generation module is disconnected first. At this time, the photovoltaic power generation module is replaced by the supercapacitor bank to provide energy and maintain the load action, its discharge waveform is recorded, and its voltage, current signal, and discharge time are analyzed.

In this study, the discharge action of the series current-limiting resistor of $1 \Omega$ is described in detail. As shown in Fig. 13, the discharge waveform can be divided into four intervals to explain the changes in voltage and current, which are described as follows: 


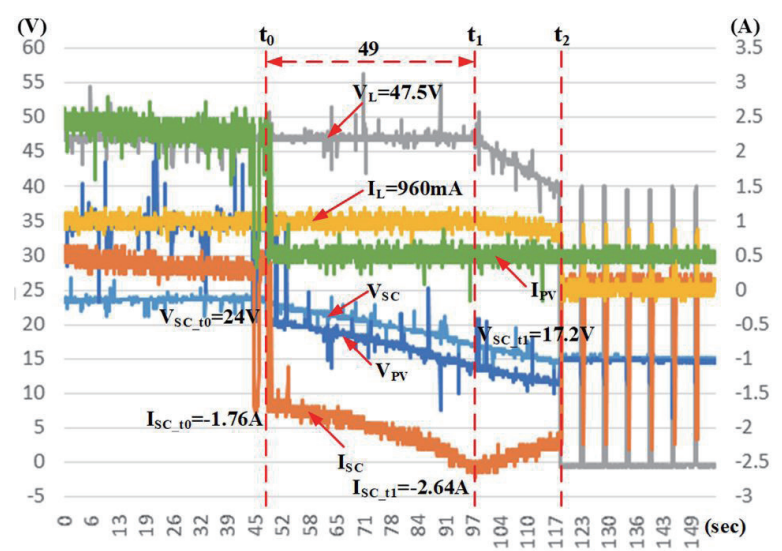

Fig. 13. (Color online) Measured waveforms of series current-limiting resistor of $1 \Omega$ during discharging.

(1) Time: $t<t_{0}$

The current of the supercapacitor bank gradually decreases to $0 \mathrm{~A}$ when the supercapacitor bank is charged to the full voltage of $24 \mathrm{~V}$. At this time, the voltage of the photovoltaic power generation module is $34.8 \mathrm{~V}$ and the current is $2.32 \mathrm{~A}$. The voltage and current of the load are still maintained at $47.5 \mathrm{~V}$ and $960 \mathrm{~mA}$, respectively. In addition, there is a phenomenon that the current of the supercapacitor bank decreases sharply in this region and then increases again. It is caused by the photovoltaic power generation module being suddenly covered by clouds during the experiment. To maintain the normal action of the load, the system will have the action of supercapacitor bank discharge.

(2) Time: $t_{0} \leq t<t_{1}$

When $t=t_{0}$, the photovoltaic power generation module is disconnected. At this time, the supercapacitor bank supplies energy to the boost converter through the maximum power point tracking converter and maintains the action of the load. The supercapacitor bank starts discharging to the load from $24 \mathrm{~V}$ and $1.76 \mathrm{~A}$, and the voltage and current at the load are maintained at $47.5 \mathrm{~V}$ and $960 \mathrm{~mA}$, respectively. Then, when $t_{0}<t<t_{1}$, the region presents the action of supercapacitor discharge bank. Its discharge waveform shows an exponential shape. When the voltage of the supercapacitor bank decreases, its discharge current gradually increases. At this time, because the supercapacitor bank provides energy to the load, the voltage and current of the load are still maintained at $48 \mathrm{~V}$ and $960 \mathrm{~mA}$, respectively.

From the above description, it can be seen that when time $t_{0}<t<t_{1}$, the system action measurement results show that when the photovoltaic power generation module is interrupted owing to short-term power supply, the supercapacitor bank can discharge and the load can maintain the required voltage, indicating that the supercapacitor bank of the system in this experiment process can act as a continuous power supply.

(3) Time: $t_{1} \leq t<t_{2}$

When $t=t_{1}$, the maximum discharge current of the supercapacitor bank is $2.64 \mathrm{~A}$, its voltage is reduced to $17.2 \mathrm{~V}$, and the load can still be maintained at $48 \mathrm{~V}$ and $960 \mathrm{~mA}$. Then, when $t_{1}<t<t_{2}$, although the supercapacitor bank in this region is still discharging, the energy 
provided is insufficient to supply the load to maintain the action of the load, so the voltage and current of the supercapacitor bank and the load gradually decrease, and the load is no longer maintained on the voltage set by the system.

From the above description, it can be seen that when time $t_{1}<t<t_{2}$, the system action measurement results show that although the supercapacitor bank has discharge action, the energy storage is gradually insufficient to supply the load, so the energy required at the load is insufficient, and its voltage and current gradually decrease.

(4) Time: $t \geq \mathrm{t}_{2}$

When $t \geq t_{2}$, although the supercapacitor bank is still discharging, it cannot provide the required energy to the load, so the voltage at the load is not maintained at the set voltage, which means that the supercapacitor bank can no longer supply energy to the load at this time. Finally, the waveform begins to show a pulse width modulation (PWM) switch. The switching action of the PWM switch is to pull the voltage to the set voltage for the converter, but the switching action of the PWM switch is presented owing to insufficient energy.

The discharge actions of the series current-limiting resistors of $1.5 \Omega$ and $1.9 \Omega$ are the same as that of the series current-limiting resistor of $1 \Omega$. Therefore, the measured values are presented in tabular form. Table 5 shows the discharge numerical analysis of the series currentlimiting resistor of $1.5 \Omega$. Figure 14 shows the measured waveform of the series current-limiting resistor of $1.5 \Omega$. Table 6 shows the discharge numerical analysis of the series current-limiting resistor of $1.9 \Omega$. Figure 15 shows the measured waveform of the series current-limiting resistor of $1.9 \Omega$.

Table 5

Discharge numerical analysis of series current-limiting resistor of $1.5 \Omega$.

\begin{tabular}{|c|c|c|c|c|c|c|}
\hline $\begin{array}{l}\text { Series current-limiting } \\
\text { resistor of } 1.5 \Omega\end{array}$ & $t<t_{0}$ & $t=t_{0}$ & $t_{0}<t<t_{1}$ & $t=t_{1}$ & $t_{1}<t<t_{2}$ & $t \geq t_{2}$ \\
\hline$\overline{V_{P V}(\mathrm{~V})}$ & 34.8 & - & & - & The energy & \\
\hline$I_{P V}(\mathrm{~A})$ & 2.24 & - & The supercapacitor & - & of the & \\
\hline$V_{S C}(\mathrm{~V})$ & 24 & 24 & bank discharges & 17.2 & supercapacitor & PWM switch \\
\hline$I_{S C}(\mathrm{~A})$ & 0.4 & -1.76 & expon & -2.56 & bank is & switching action \\
\hline$V_{L}(\mathrm{~V})$ & 47.5 & 47.5 & 47.5 & 47.5 & insufficient to & \\
\hline$I_{L}(\mathrm{~mA})$ & 960 & 960 & 960 & 960 & supply the load. & \\
\hline
\end{tabular}

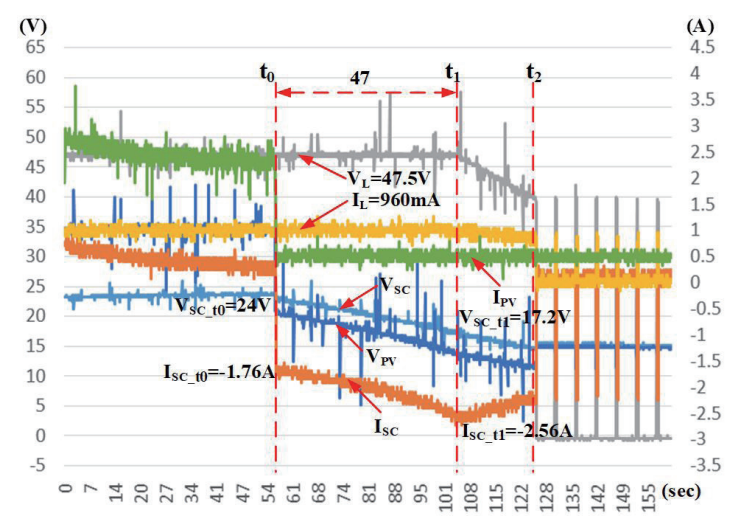

Fig. 14. (Color online) Measured waveforms of series current-limiting resistor of $1.5 \Omega$ during discharging. 
Table 6

Discharge numerical analysis of series current-limiting resistor of $1.9 \Omega$.

\begin{tabular}{|c|c|c|c|c|c|c|}
\hline $\begin{array}{l}\text { Series current-limiting } \\
\text { resistor of } 1.9 \Omega\end{array}$ & $t<t_{0}$ & $t=t_{0}$ & $t_{0}<t<t_{1}$ & $t=t_{1}$ & $t_{1}<t<t_{2}$ & $t \geq t_{2}$ \\
\hline$\overline{V_{P V}(\mathrm{~V})}$ & 34.8 & - & & - & The energy & \\
\hline$I_{P V}(\mathrm{~A})$ & 2.24 & - & The supercapacitor & - & of the & \\
\hline$V_{S C}(\mathrm{~V})$ & 24 & 24 & bank discharges & 20 & supercapacitor & PWM switch \\
\hline$I_{S C}(\mathrm{~A})$ & 0.4 & -2.24 & exponen & -2.8 & bank is & switching action \\
\hline$V_{L}(\mathrm{~V})$ & 47.5 & 47.5 & 47.5 & 47.5 & insufficient to & \\
\hline$I_{L}(\mathrm{~mA})$ & 960 & 960 & 960 & 960 & supply the load. & \\
\hline
\end{tabular}

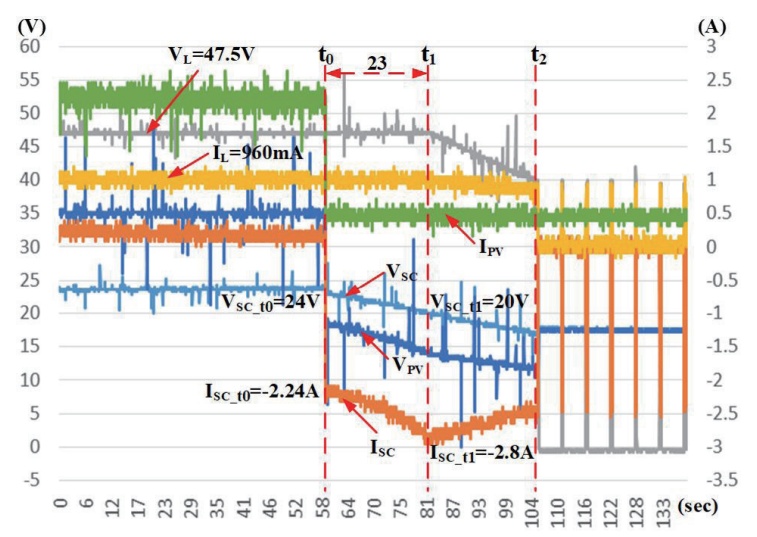

Fig. 15. (Color online) Measured waveforms of series current-limiting resistor of $1.9 \Omega$ during discharging.

According to the above-measured waveforms, it can be concluded that when the photovoltaic power generation module in the system is interrupted for a short time, the supercapacitor bank can maintain the action of the load. Its voltage and current are maintained at $47.5 \mathrm{~V}$ and $960 \mathrm{~mA}$, respectively, for about 49, 47, and $23 \mathrm{~s}$. This also indicates that the discharge times of the supercapacitor bank are 49,47 , and $23 \mathrm{~s}$.

Finally, according to the measurement results of the charge/discharge parts of the supercapacitor bank mentioned above, under three different current-limiting resistors in series, for the same supercapacitor bank and load, the charging time required for the supercapacitor bank, and the short interruption of the photovoltaic power generation module in the system, the supercapacitor bank can maintain load-side time, as shown in Table 7. In this system, although the discharge times of the series current-limiting resistors of $1 \Omega$ and $1.5 \Omega$ are only $2 \mathrm{~s}$ different, there is a difference of $14 \mathrm{~s}$ in charging time. Moreover, the resistance in series in the series current-limiting resistor of $1 \Omega$ is smaller. It can charge a supercapacitor bank with a high charging current. This means that the charging time can be shortened and the power loss in the system can be reduced. When the series current-limiting resistor is $1 \Omega$, better charging/ discharging times will be obtained. Under the test conditions of series resistance of $1 \Omega$ selected in this study, there will be better charging/discharging times with the same result. 
Table 7

Charging/discharging times of supercapacitor bank with different series current-limiting resistors.

\begin{tabular}{lcc}
\hline Series current-limiting resistor & Charging time (s) & Discharging time (s) \\
\hline $1 \Omega$ & 76 & 49 \\
$1.5 \Omega$ & 90 & 47 \\
$1.9 \Omega$ & 187 & 23 \\
\hline
\end{tabular}

\section{Conclusion}

In this study, we presented the application of a supercapacitor in the photovoltaic power generation system. The control circuit includes a maximum power point tracking converter, a boost converter, a Hall element, a waveform recorder, and a supercapacitor bank. Using 60 $2.7 \mathrm{~V}$ and $50 \mathrm{~F}$ supercapacitors, 10 series, 6 parallel, and $27 \mathrm{~V}$ and $30 \mathrm{~F}$ supercapacitor banks as energy storage devices, and using a boost converter and a resistor of $50 \Omega$ as the load end, the supercapacitor bank is charged and discharged by photovoltaic energy. When the initial voltages of the supercapacitor bank are 19.6, 19.7, and 19.2 V when the sunshine is sufficient to provide enough load for the photovoltaic power generation system, the charging times for the supercapacitor bank are about 76,90 , and $187 \mathrm{~s}$, respectively. If the photovoltaic power generation system is interrupted for a short time, the supercapacitor bank can still provide energy to the load. About 49, 47, and $23 \mathrm{~s}$ can be maintained, respectively, and the charging/ discharging times of the series current-limiting resistor of $1 \Omega$ are the best results. The test results show that the control system using the supercapacitor bank as an energy storage device can effectively improve the intermittent output and voltage instability of photovoltaic power generation, and ensure the power quality and power supply continuity of the photovoltaic power generation system.

\section{Acknowledgments}

This research was partially supported by the Ministry of Science and Technology of Taiwan, under Grant MOST 107-2221-E-167-015.

\section{References}

1 M. Z. S. El-Dein, M. Kazerani, and M. M. A. Salama: IEEE Trans. Sustainable Energy 4 (2013) 145. https:// doi.org/10.1109/TSTE.2012.2208128

2 L. Maheswari, P. S. Rao, N. Sivakumaran, G. S. Ilango, and C. Nagamani: IET Power Electron. 10 (2017) 1087. https://ieeexplore.ieee.org/document/7989805

3 U. Manandhar, N. R. Tummuru, S. K. Kollimalla, A. Ukil, G. H. Beng, and K. Chaudhari: IEEE Trans. Ind. Electron. 65 (2018) 3286. https://doi.org/10.1109/TIE.2017.2750622

4 E. Du, N. Zhang, B. Hodge, Q Wang, C. Kang, B. Kroposki, and Q. Xia: IEEE Trans. Power Syst. 33 (2018) 6630. https://doi.org/10.1109/TPWRS.2018.2834461

5 S. Castano-Solis, L. Gauchia, D. Serrano-Jimenez, and J. Sanz: IEEE Trans. Energy Convers. 32 (2017) 620. https://doi.org/10.1109/TEC.2016.2646800

6 Z. Cabrane, M. Ouassaid, and M. Maaroufi: IET Renewable Power Gen. 11 (2017) 1157. https://ieeexplore.ieee. org/document $/ 7984978$

7 Z. Cabrane, M. Ouassaid, and M. Maaroufi: Proc. 2017 Int. Conf. Green Energy Conversion Systems (IEEE, 2017). https://doi.org/10.1109/GECS.2017.8066128 
8 K. Yao, S. Chen, M. Rahimabady, M. S. Mirshekarloo, S. Yu, F. E. H. Tay, T. Sritharan, and L. Lu: IEEE Trans. Ultrason. Ferroelectr. Freq. Control 58 (2011) 1968. https://doi.org/10.1109/TUFFC.2011.2039

9 S. Subramanian, M. A. Johny, M. M. Neelanchery, and S. Ansari: IEEE Trans. Power Electron. 33 (2018) 10410. https://doi.org/10.1109/TPEL.2018.2810889

10 J. Ho, T. R. Jow, and S. Boggs: IEEE Electr. Insul. Mag. 26 (2010) 20. https://doi.org/10.1109/ MEI.2010.5383924

11 K. Liu, C. Zhu, R. Lu, and C. C. Chan: IEEE Trans. Plasma Sci. 41 (2013) 1267. https://doi.org/10.1109/ TPS.2013.2251363

12 A. Kuperman, M. Mellincovsky, C. Lerman, I. Aharon, N. Reichbach, G. Geula, and R. Nakash: IEEE Trans. Power Electron. 29 (2014) 5399. https://doi.org/10.1109/TPEL.2013.2292674

13 R. German, A. Hammar, R. Lallemand, A. Sari, and P. Venet: IEEE Trans. Power Electron. 31 (2016) 548. https://doi.org/10.1109/TPEL.2015.2408457

14 M. Uno and A. Kukita: IEEE Trans. Power Electron. 30 (2015) 3077. https://doi.org/10.1109/ TPEL.2014.2331312

15 M. Uno and K. Tanaka: IEEE Trans. Ind. Electron. 59 (2012) 4704. https://doi.org/10.1109/TIE.2011.2182018

16 A. Khaligh and Z. Li: IEEE Trans. Veh. Technol. 59 (2010) 2806. https://doi.org/10.1109/TVT.2010.2047877

17 S. Subramanian, M. A. Johny, M. M. Neelanchery, and S. Ansari: IEEE Trans. Power Electron. 33 (2018) 10410. https://doi.org/10.1109/TPEL.2018.2810889

18 S. K. Kollimalla, M. K. Mishra, and N. L. Narasamma: IEEE Trans. Sustainable Energy 5 (2014) 1137. https:// doi.org/10.1109/TSTE.2014.2336896

19 R. E. Araújo, R. de Castro, C. Pinto, P. Melo, and D. Freitas: IEEE Trans. Veh. Technol. 63 (2014) 3062. https:// doi.org/10.1109/TVT.2014.2318275

20 A. S. Sengupta, S. Satpathy, S. P. Mohanty, D. Baral, and B. K. Bhattacharyya: IEEE Consum. Electron. Mag. 7 (2018) 50. https://doi.org/10.1109/MCE.2018.2835958 